\title{
THE CHARACTERISTICS OF ENGLISH TERMS STRUCTURE IN ARCHITECTURE AND CONSTRUCTION INDUSTRY
}

\author{
Mariia Ivanchenko \\ $\mathrm{PhD}$ in Philology, Associate Professor, Senior Lecturer at the Department \\ of Foreign Languages and Translation Studies, Lviv State University of Life Safety, Ukraine \\ e-mail: Ivalexiv1979@ukr.net, orcid.org/0000-0001-7363-4600
}

\section{Summary}

The article deals with structural typology in architecture and construction terminology. Modern linguists pay great attention to the study of terminological units in different branches of industry in modern world. The rapid growth of terms number in architect and construction requires its study, description and systematization.

The current body of research provides clear evidence of much attention being paid to the architecture and construction industry itself, and its terminology in particular. The task of the research was to compare the structural features and identify the quantitative ratio of components in architecture and construction terms. Consequently, the object of research was the English terminology of architecture and construction industry, and the subject concerned the structural peculiarities of the English architecture terms. English samples of architecture and construction terms from internet resources have been analysed. Structural peculiarities of English architecture and construction terms have been studied and defined by the methods of comparative and structural analysis.

Keywords: structural typology, professional terms, component, multicomponent term, nomination, abbreviation.

\section{DOI: https://doi.org/10.23856/3845}

\section{Introduction}

It is you known, the vocabulary is the most permeable, volatile and dynamic side of language. A distinctive and characteristic feature of any language vocabulary is its ability to grow indefinitely due to new words and new meanings, which are formed in different ways. During the formation of a certain knowledge or activity field, the formation of terminology takes place (Bialyk, 2019). A review of the literature of modern terminological research has shown that actively developing terminologies that constantly supply extensive material for terminological research and therefore need to be streamlined and standardized are of particular interest (Bialyk, 2019).

The spread of terminological vocabulary in people's speech outside of communication situations related to professional activities is a peculiar sign of our time. In modern conditions, the use of terms is no longer the prerogative of specialists in a particular field. The indicated trend is also true with regard to vocabulary of construction and architecture. Architectural terminology is regularly used in a variety of contexts and is in a state of intensive development in the context of modern progress.

The material of the study is a text corpus of articles devoted to information on building industry, architecture and interior design. Text material extracted from online versions of periodicals "Journal of Architectural Engineering"; "Designer plus Builder"; "Dezeen"; "Architect". The analysis involved publications from 2017 to 2019. 


\section{General characteristics of architecture and construction terminology}

The term "architecture" is traditionally referred to in dictionaries as "the art and technique of designing and building, as distinguished from the skills associated with construction. The practice of architecture is employed to fulfill both practical and expressive requirements, and thus it serves both utilitarian and aesthetic ends" (Encyclopedia Britannica). This concept differs from the concept of construction in its artistic content, which gives it a different definition: "character, style of building", "artistic nature of the building" (Encyclopedia Britannica). Within the general concept of architecture, it is noted that architecture, as the art of designing structures, is symbolic and reflects not only the culture of a particular period, the religious symbolism of the nation, but also the spiritual intent of its creator.

Previously, the problem of construction and architectural vocabulary study has not been fully developed in modern scientific research, and is mainly conducted within the framework of linguistic study of language. Construction and architectural vocabulary refers to the linguistic units that nominate the notion of architecture and construction and which function in the scientific field as well as in the artistic (poetic, prose) text and form part of a common literary language. A architecture and construction term is a word that refers to a specific concept of the architecture and construction subject. In special use (in scientific language, in scientific discourse) the building and architectural term is unambiguous, not emotional, stylistically neutral.

The linguostructural analysis of the of modern architecture and construction sublanguage has led to the conclusion that, as a small linguostructural subsystem, it possesses universal properties characteristic for common language and differential properties that are absent in a common language.

The differential properties of the architecture and construction sublanguage include its consistency, finiteness and completeness.

The characteristic stylistic features of architecture and construction sublanguage are considered emotional and subjective-evaluative neutrality, generalization and presentation brevity. The substantial differences between this sublanguage and the common language are manifested mainly in lexis.

Architecture and construction sublanguage lexis and occupies a special place in a number of special languages. Modern architecture and construction sublanguage has not only a limited set of terminological vocabulary expressing building and architectural concepts, but also a number of structural and functional features, as well as expressing basic building concepts that are fundamental to the whole human society. We believe that the information, which is recorded in the mentioned terminological units, accumulates the information of the language and culture as semiotic components that constitute a holistic world image (Aimenova, 2019).

For example, the lexemes "building", "construction", "housing", "environment", "design", "module" and others designate universal concepts that have always been and will be used in various societies as means of nominating processes and results of person's activities.

It is legitimate to assert that the specifics of the architecture and construction sublanguage lexical units are determined by terms that express the corresponding categorical concepts and are conditionally divided into common, general scientific and terminological subsystems.

Terminological vocabulary is considered to be the totality of terms necessary to express certain concepts of a special field; the term is traditionally understood as a word (phrase), meaning the concept of a special knowledge or activity field and used in professional conditions. 
It is known that the term can exist only as an element of the term system. Terminology is a set of terms that adequately express a theory concepts system that relates to a specific area of human knowledge or activity (Teleky, 2019).

Special fields of knowledge and human activity are modeled by concepts systems, which are first and foremost elements of a particular knowledge area, and are explicated in two manifestations - in the aggregate of these concepts definitions and in a terms set. Therefore, we can say that the terminological system is a linguistic model of a specific knowledge area. Among the features of term systems as a types of abstract systems are system-wide, logical, linguistic and model-forming (Novikova, 2017).

\section{One-component architecture and construction terms}

Next, we will try to give a structural characterization of architecture and construction terminology. The terminology study currently pursues not only scientific, but practical goals as well. That is why not only a description of the architecture and construction terminological system is considered to be important, but also a study of the formation methods and ways to replenish mentioned terminology. Scientists distinguish different ways of terms formation, depending on productivity. The main source of creating new terms, enriching the terminological fund and improving individual terminological language systems are its internal resources. The vocabulary replenishment of the science language with new words occurs through the use of morphemes existing in the language and their new combination (Fedurko, 2019).

The structural analysis of the architecture and construction terms actual material was carried out, where the following types were identified: one-component (simple and derivative), multi-component, abbreviations.

Analysis of architecture and construction terms sample concerning their structure showed that the most common are simple terms. Derived terms were less represented. The most productive way to form derivative terms is affixation, we have distributed suffixes as follows: er 35\% - camber, curvature, gutter, cover, skyscraper, girder, sleeper, baluster; ing 23\% - bending, buckling, projecting, reentering, lighting, supporting, heating, drafting, drawing, ceiling, adjoining; tion $10 \%$ - deflection, projection, condensation, conditions, fenestration, abnodation; ent $8 \%$ - abutment, basement; ance 7\% - balance, abeyance, ant 5\% - pendant, rampant, or 5\% - exterior, agitator; el 3\%-barrel, tunnel, mandrel; out 2\%-layout; ture 2\%-curvature, moisture, structure.

\section{Multicomponent architecture and construction terms}

The language nomination in architecture and construction sublanguagenis distinguished by the presence of a large number of terms, including multicomponent terminological units. In general, such units are transparently motivated and therefore the most widely distributed in rapidly developing fields of knowledge. Architecture and construction is one of the relatively dynamically developing areas of activity in the modern world, which at the same time has very deep roots. Moreover, the lexical layer of this group is being constantly updated with new terms in English.

The difficulty lays in the fact that the multicomponent phenomenon essence is characterized by a plurality of viewpoints. Terms that have several lexical units in their composition are called differently: terms-chains, multiword terms, polynomial terms, ambiguous terms, poly-lexical terms.

In linguistics, two-component and multicomponent terms are distinguished depending on the number of internal components and the type of relationship between the constituent parts. Such 
group of terms is the optimal language tool in the field of actual nomination in modern science and, due to its large semantic capacity, is the most important lexical constituent of a scientific text.

According to L. N. Belyaeva, the formation of multicomponent terms is a binary process, to a great extent, depends on how the nomination occurs: either as a process of gradual complication and specification of an object nomination (gradual complication of the nominal structure with the addition and change of the core characteristics); either as a process of sequential compression (Belyaeva, 2007). The main characteristics of such combinations are: limited expressivity and imagery; the potential ability to condense over time into single-word names.

Multicomponent terms, or multicomponent terminological combinations, in the English language, according to some authors, include in their ranks and terms issued through a hyphen. These terms are characterized by structure complexity and the components ambiguity: site-assembled, water-bound macadam etc.

The architecture and construction sublanguage analysis of the multicomponent terms in English showed that two, three, four, five, six, and seven-component terms are used in the texts of this direction. The following data were obtained as a percentage: two-component 22\%: domestic building; arched concrete dam; multistoried building; residential building; sectional building; three-component - 21\%: airtight building construction; aseismic building constructions; block building construction; four-component - 21\%: balloon frame building construction; platform frame building construction; safe maintenance of construction machinery; five-component - 5\%: cantilever arched building construction girder; to show building construction element fracture; brittle building construction element fracture, double crank construction materials press; six-component - 2\%: plane strain building construction element fracture; stress-corrosion building construction element fracture; building construction element maintenance processing and repair; errors in the building construction element maintenance processing.

\section{Architecture and construction abbreviations}

Due to the components increase, abbreviations are being actively used. The appearance and widespread use of them is primarily associated with their use convenience. However, the strong saturation of the text with abbreviations often leads to difficulties in interpreting. The presence of a significant abbreviations proportion is a typological feature of the term system under consideration.

As scientists note, the abbreviation is used to achieve the necessary brevity of the term; it arises as a result of word combination transformation into a compound word (Malenika, Fabianic, 2013).

Two types of abbreviations were figured out, these are initialisms - a sequence of capital letters, each of which is pronounced separately, and shortenings when certain sound segments are removed from the word composition.

The analysis showed, that the number of initialisms in construction terminology prevails, their structure is quite simple, they are formed by the term combination capital letters. For example - ACB (asbestos-cement board); $A C M$ (advanced composite materials); $A D W$ (air-dried wood); GERAM (Generalized Enterprise Reference Architecture and Methodology), LALAC (Local Architectural Conservation Advisory Committee), ADW (air-dried wood), DD (Dutch door), FSTC (Field sound transmission class), MLMA (Metal Lath Manufacturers Association), $A$ and $M$ (assembly and maintenance); AAW (acetylene air welding). 
The factual material showed that shortenings that takes place when all vowel sounds are omitted from a term, for example, $R F$ (roof); $R M$ (room); wd (wood); fbr (fibro). Next, we highlight syllabic shortening was figured out as well, which is understood as a shortening of syllables or fragments of the original phrase, forming syllables within the abbreviation. For example: COL (column); DEML (demolition); elev (elevator); soln (solution); CONTR (contractor); solv (solvent); CATW (catwalk); ct (cement); bitn (bitumen). One more shortening type was pointed out consisting of the initial, middle and final letters of one word or phrases, for example - agt (agent); ct (cement); Lbr (lumber); drlg (drilling); eq (equipment; bdg (building); BRK (brick); BSMT (basement); CLG (ceiling).

The fulfilled analysis of the English architecture and construction terms made it possible to establish that this group of terms is nominative units that express capacious names of scientific phenomena and concepts. Moreover, they play the role of one of the most important scientific text constituents, ensuring the accurate content transfer. The results of the architecture and construction terms structure analysis showed that simple terms amounted to $61 \%$; derived terms $-21 \%$; multicomponent terms $-29 \%$; abbreviations $-10 \%$.

\section{References}

Aimenova, M., Ospanova, A., Rakhimova, A., Sarsembayeva, A. Mazhit. Z. (2019). Phraseological terminology in the English economic discourse. XLinguae. European Scientific Language Journal, 1, 228-238. Retrieved from: http://www.xlinguae.eu/. doi: 10.18355/XL.2019.12.01.18 Belyaeva, L.N., (2007). Theory and practice of translation. SPb.: LLC Book House.

Bialyk, V. D., (2019). Word-formation Background of a Lexical Neo-Quantor Epistemology. Efficiency level and the necessity of influence of philological sciences on the development of language and literature : collective monograph, (pp. 1-18). Lviv-Toruń : Liha-Pres. doi: https://doi.org/10.36059/978-966-397-170-4/1-17

Encyclopedia Brittanica. Retrieved from: https://www.britannica.com/topic/architecture Fedurko, M. Yu., (2019). Morphonological units in the system of Ukrainian word-formation from the noun. Traditions and innovations in teaching philological disciplines : collective monograph, (pp. 72-89). Lviv-Toruń : Liha-Pres. doi: https://doi.org/10.36059/978-966-397131-5/72-88

Malenica, F., Fabijanić, I., (2013). Abbreviations in English Military Terminology. Brno Studies in English, Volume 39, 1, 59-63. ISSN 0524-6881 doi: 10.5817/BSE2013-1-4

Novikova, E., Mityagina, V., Charfaoui, E. (2017). Pragmatics of terminological nomination: tourism management. XLinguae. European Scientific Language Journal, 3, 285-299. Retrieved from: http://www.xlinguae.eu/. doi: 10.18355/XL.2017.10.03.23

Teleky, M. M. (2019). Eponymic terminological collocations in sublanguage of infectology. Scientific journal of the Lviv State University of Life Safety "Philological Periodical of Lviv", 5, 152-159. doi: https://doi.org/10.32447/2663-340X-2019-5-26

Yurko N. A., Styfanyshyn I. M., Romanchuk O. V. (2019). The characteristics of english terms structure in tourism industry. Scientific journal of the Lviv State University of Life Safety "Philological Periodical of Lviv”, 5, 178-183. doi: https://doi.org/10.32447/2663-340X-2019-5-30 